\title{
O governo da e pela kultura. Complexos locais de governança na formação do Estado em Timor-Leste
}

Kultura: Local Governance Complexes in State Formation in Timor-Leste Le gouvernement de la et par la kultura. Complexes locaux de gouvernance dans la formation de l'État au Timor-Leste

\section{Kelly Silva}

\section{(2) OpenEdition}

\section{Journals}

Edição electrónica

URL: http://journals.openedition.org/rccs/5727

DOI: $10.4000 /$ rccs. 5727

ISSN: 2182-7435

Editora

Centro de Estudos Sociais da Universidade de Coimbra

\section{Edição impressa}

Data de publição: 1 Setembro 2014

Paginação: 123-150

ISSN: 0254-1106

\section{Refêrencia eletrónica}

Kelly Silva, «O governo da e pela kultura. Complexos locais de governança na formação do Estado em Timor-Leste », Revista Crítica de Ciências Sociais [Online], 104 | 2014, colocado online no dia 23 setembro 2014, criado a 19 abril 2019. URL : http://journals.openedition.org/rccs/5727 ; DOI $10.4000 /$ rccs. 5727 


\section{KELLY SILVA}

\section{O governo da e pela kultura. Complexos locais de governança na formação do Estado em Timor-Leste*}

Este artigo discute certos modos pelos quais o Estado leste-timorense tem lidado com elementos dos complexos locais de governança, chamados kultura desde o ponto de vista local. A partir da análise de usos recentes do tara bandu e das dinâmicas de estruturação do poder local, argumento que o reconhecimento e a incorporação de dimensões dos complexos locais de governança têm se dado de modo a transformá-las em vias para geração de efeitos de pacificação, integração e monopolização do poder. Ao mesmo tempo, os usos da kultura servem à transposição e internalização de práticas e projetos modernos de organização social e subjetivação. Exploro as críticas à partidarização das eleições locais como um ato de resistência e agência de setores das populações rurais aos projetos de apropriação política de aspetos de suas dinâmicas de reprodução social pelas elites nacionais baseadas em Díli.

Palavras-chave: cultura; formação do Estado; governação; poder local; tara bandu; Timor-Leste.

Este ensaio aborda algumas tendências e tensões que estruturam as tentativas de apropriação e subversão de elementos dos complexos locais de governança, chamados kultura desde o ponto de vista local, por parte do Estado leste-timorense. Tal exercício analítico estrutura-se a partir do diálogo com certa sociologia política voltada à compreensão dos processos de formação dos Estados nacionais e coloniais, com a produção bibliográfica recente sobre o tema para o caso leste-timorense e com minhas próprias experiências

\footnotetext{
* Este artigo é um produto da linha de pesquisa intitulada Processos de invenção, transposição e subversão da modernidade, que coordeno no Departamento de Antropologia da Universidade de Brasília, Brasil. Agradeço ao CNPq por prover recursos, mediante os processos 201269/2011-2, 307043/2012-6 e 401609/2010-3, que permitiram a produção das informações aqui analisadas, bem como ao Instituto Nacional de Estudos sobre Administração Institucional de Conflitos (INEAC). Sou grata também aos meus colegas docentes e discentes pelas críticas ao meu trabalho, especialmente a Daniel S. Simião, Mariza G. S. Peirano e Alexandre Jorge Medeiros Fernandes. Agradeço ainda a todos os meus interlocutores leste-timorenses, e aos pareceristas da Revista Crítica de Ciências Sociais.
} 
de trabalho de campo. Tomando por objeto de discussão alguns dos recentes usos da prática chamada de tara bandu ('dependurar proibições', em tradução literal do tétum) e as dinâmicas de estruturação do poder local no país, argumento que o reconhecimento e a incorporação de dimensões dos complexos locais de governança têm se dado de modo a transformá-las em vias para geração de efeitos de pacificação, integração e monopolização do poder, típicas dos processos de formação estatal. Ao mesmo tempo, os usos dos complexos locais de governança servem à transposição e internalização de práticas e projetos modernos de organização social e subjetivação. ${ }^{1}$ Ao situar tais fenômenos numa perspectiva regional e de longa duração eles perdem parte de sua excepcionalidade. Apresentam-se, antes, como uma continuação das táticas parasitárias pelas quais as administrações estatais têm se capilarizado em Timor-Leste e alhures, dando origem a práticas híbridas de governança. ${ }^{2}$ Tais fatos, contudo, não ocorrem sem resistência e tensões. A esse respeito, sugiro que as críticas à partidarização das eleições locais podem ser lidas como um ato de resistência e agência de setores das populações rurais leste-timorenses aos projetos de apropriação política de aspectos de suas dinâmicas de reprodução social pelas elites nacionais baseadas em Díli. Entre outras coisas, tal fenômeno se deve ao fato de a concorrência partidária desafiar, em alguns casos, preceitos que organizam o exercício e a distribuição de poder localmente.

Denomino complexos locais de governança os conjuntos de dispositivos de regulação, controle, exercício da agência e reprodução social de grupos e indivíduos sobre o mundo, de composição vária, que se configuram muitas vezes como fatos sociais totais ${ }^{3}$ e se ancoram em bases de legitimidade

\footnotetext{
${ }^{1}$ Inspirada pela ampla bibliografia histórica e etnográfica sobre os modos pelos quais tais projetos e processos de modernização ganham vida social, utilizo a palavra 'modernidade' como uma categoria analítica polissêmica e indicativa, que evoca expectativas relacionadas a figurações sociológicas e morais orientadas por igualitarismo, individualismo, secularismo, racionalização e industrialização. Contudo, a vida social de tais figurações está sempre condicionada a múltiplas mediações e apropriações, nunca se realizando plenamente (Dumont, 1983; Latour, 1994).

2 No âmbito deste artigo, os usos que faço dos termos 'parasitária' e 'parasitação' inspiram-se diretamente no trabalho de Roque (2010a). Este autor qualifica como mútuo parasitismo uma forma de sociação (dentre outras possíveis) entre agências do Estado português e instituições indígenas, caracterizada pela coexistência, interdependência, interpenetração, hostilidade, assimetria e manutenção de limites entre ambas, a partir da qual cada uma das partes extrai recursos de várias ordens para sua respectiva reprodução. Em sua concepção original, a ideia de mútuo parasitismo foi cunhada para qualificar fenômenos coloniais, exclusivamente, e não comporta projetos de mudança nas entidades sobre as quais se realiza. No entanto, seus potenciais cognitivos parecem-me adequados para dar sentido também aos fatos pós-coloniais aqui discutidos.

${ }^{3}$ Mauss (1974) qualifica como fatos sociais totais os fenômenos cuja existência e implicações derivam de e afetam vários domínios de sociabilidade, ao mesmo tempo. Tratam-se, assim, de fatos que são concomitantemente religiosos, jurídicos, políticos e econômicos.
} 
múltiplas, as quais podem se manifestar de modo combinado ou isolado. Adoto o termo 'complexos' em vez de 'sistemas' para evocar o potencial de que as partes que os compõem não se relacionam necessariamente de modo organizado, harmônico ou hierarquizado, tendo autonomia relativa umas diante das outras, podendo, inclusive, ser mobilizadas concomitantemente. Além disso, o termo 'complexos locais' sugere que tais coletivos de governança podem ter configuração distinta de lugar para lugar, a qual reflete, quase sempre, sua respectiva história de conformação. Tal complexo é composto por diferentes agentes e agências: 1. instituições que estruturam os modos locais de organização social, das quais destaca-se a casa; 2 . saberes rituais e suas técnicas (sacrifícios, manejo das palavras com o objetivo, por exemplo, de imposição de proibições para fins de governo, rituais de ciclo de vida ou resolução de conflitos); 3 . posições de autoridade para mediação com instituições do Estado e da Igreja (chefes de aldeia, professor catequista, por exemplo) e de mediação com forças ou entidades espirituais (sacerdotes rituais, bruxas, adivinhadores), entre outros. Assim, a governança emerge como efeito de poder derivado das relações entre os elementos que compõem tais complexos. Desde o ponto de vista de Díli, a referência a elementos ou à totalidade dos complexos locais de governança se dá pela mobilização dos termos lisan, adat, usos e costumes ou ainda kultura.

As tentativas de apropriação dos Estados coloniais e pós-coloniais de elementos dos complexos locais de governança geram governança híbrida, entendida ao longo do artigo na acepção de Boege et al. (2009: 17). Segundo tais autores, a governança híbrida se caracteriza pela coexistência de instituições e dispositivos de poder originários, de um lado, de estruturas estatais coloniais e nacionais e, de outro, de dinâmicas indígenas de organização social. Tais instituições cooperam e ao mesmo tempo disputam entre si espaço político, estando ambas sujeitas aos discursos e dispositivos de entidades transnacionais de governança.

Embora os complexos locais de governança sejam, em parte, produto de apropriações e subversões de tecnologias de governo coloniais e pós-coloniais (McWilliam, 2008; Cummins, 2010; Roque, 2012), eles são considerados, muitas vezes, como genuinamente autóctones pelas populações nativas. A presumida autoctonia dos mesmos é a principal variável que levo em conta para considerá-los locais e opto por denominá-los locais em vez de costumeiros para distanciar-me de perspectivas analíticas que não dão a devida atenção ao fato de que o domínio do costume tem sido edificado e negociado a partir de encontros entre diferentes agentes e agências de governo ao longo do tempo. 
O presente artigo está estruturado em três seções, além da conclusão. Na primeira, resgato alguns traços dos processos de construção estatal, tal como sistematizados por Elias (1993), Poggi (1978) e Mamdani (1998), entre outros, de modo a explicitar fenômenos que tomo como referência para pensar nas dinâmicas contemporâneas de construção do Estado em Timor-Leste. À parte de todas as diferenças que caracterizam tais fenômenos em diversos contextos e temporalidades, sublinho o que há de comum a todos eles: a integração de níveis inferiores de autoridade e de suas tecnologias de governança por meio de uma incorporação seletiva e transformativa. A seguir, são analisadas tendências e tensões das dinâmicas de institucionalização do poder local no país. Demonstro então a posição liminar das autoridades do poder local - Chefes de Suco e Chefes de Aldeia diante do Estado e as múltiplas fontes de legitimidade da qual derivam seus poderes. Indico também as ansiedades administrativas que informam os esforços do Estado em controlar as práticas locais de resolução de conflitos e atos de resiliência e agência das elites rurais diante de projetos de partidarização da dinâmica política local. Na terceira seção, alguns dos usos contemporâneos das práticas de tara bandu são objetos de atenção. A esse respeito, ressalto como tais usos servem a propósitos de pacificação e domesticação da conduta, bem como ao fortalecimento da própria estrutura administrativa do Estado. A partir das iniciativas de controle das práticas rituais de reprodução social previstas no tara bandu realizado em Ermera em 2012, indico como o governo da e pela Kultura é um meio pelo qual se busca produzir corpos e outras modalidades de recursos voltados à produção para o e pelo trabalho. Na conclusão, além de fazer uma síntese dos argumentos expostos, situo os fenômenos aqui discutidos em um contexto mais amplo relacionado a processos de objetivação da cultura por vários agentes políticos, cujos efeitos são imprevisíveis.

\section{Formação do Estado como integração, monopolização e reconfiguração de tecnologias de governo}

Processos de monopolização e integração política, territorial e tributária, com centralização administrativa e legal. Eis alguns fenômenos que conformaram as dinâmicas de construção do Estado absolutista que partiram de uma Europa feudalizada. Nos termos de Poggi (1978), o curso de constituição do Estado esteve relacionado à centralização do business of rule, de modo que a sociedade política representada pelo Estado se constitui a partir da reunião de grupos sociais secundários, sujeitos agora à mesma autoridade, independente, ela própria, de qualquer outra superiormente constituída (Durkheim, 1983: 41). 
Tais processos foram produzidos como efeitos de negociações e disputas que ocorreram em uma escala de longa duração, das quais eram ativos participantes autoridades das mais diversas, de senhores feudais a quadros eclesiais, que então exerciam seu poder sobre porções territoriais que vieram ao longo do tempo a ser integradas, não sem conflitos, aos territórios estatais administrados hegemonicamente por uma única Casa (Elias, 1993: 87-90). À parte de toda a complexidade envolvida em tais processos históricos, desejo sublinhar o fato de que a monopolização do business of rule foi sendo gerada por negociações e disputas com autoridades preestabelecidas na gênese do Estado na Europa, tendo implicado muitas vezes a incorporação das mesmas, em diferentes graus e sob distintas categorias e condições, em uma rede maior de interdependência. As transformações das relações entre Estado e Igreja são exemplares a esse respeito, tendo produzido a própria diferenciação entre poderes religioso e secular, entre outros efeitos de reconfiguração (Dumont, 1977; Elias, 1993: 131, 157-59).

A incorporação seletiva de autoridades preestabelecidas (e dos territórios sob suas jurisdições) em uma rede maior de interdependência foi um recurso político importante também na conformação das administrações coloniais em diferentes partes do mundo, sobretudo em suas configurações na forma de indirect rule. Tal processo deu-se mediante diferentes técnicas e em graus distintos de profundidade, no tempo e no espaço.

A constituição do governo indireto deu-se mediante a incorporação de autoridades preexistentes na estrutura das administrações coloniais de modo a transformá-las, ao longo do tempo, em representantes locais do Estado colonial, dando origem ao que Mamdani (1998) chama de despotismo descentralizado. A tais autoridades foi delegado, em muitos casos, o poder de administrar tudo o que dizia respeito ao costume, à tradição, por meio do que passou a ser chamado de direito consuetudinário. Nesse processo, o que era costumeiro ou tradicional passou a ser definido a partir de negociações entre um conjunto crescente de atores, cobrindo, por vezes, questões que nada tinham de costumeiras, como pagamento de impostos, contratos laborais, passes de trânsito, entre outros (Mamdani, 1998: 123). Assim, o campo semântico do que era considerado consuetudinário foi definido em resposta aos interesses em jogo nestes contextos. Um dos interesses mais importantes dizia respeito à necessidade de transformar as populações nativas e outros recursos locais em insumos para expansão da exploração capitalista (ibidem: 75 ).

Dos complexos processos envolvidos nestes empreendimentos é importante reter, para fins desta análise, os efeitos deles derivados. A partir de um determinado momento o Estado colonial tomou para si a função e o poder 
de definir o que era a tradição, o que era o costume e o direito consuetudinário, num esforço de monopolização e homogeneização dos instrumentos de governo. Assim, o que começou como apropriações parasitárias dos complexos locais de governança, produziu, ao longo do tempo, projetos de monopolização dos mesmos.

Para o caso do Timor Português, os trabalhos de Roque têm demonstrado o quanto a construção do governo colonial, sobretudo entre os finais do século XIX e início do século XX, se ancorou, relativamente, nas divisões

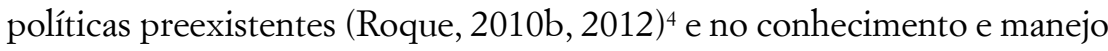
dos ditos usos e costumes locais, de modo que partes ou a totalidade de certas tecnologias coloniais de governo procuravam espelhar, ao menos enquanto projeto, as práticas indígenas de governança (Roque, 2011). A administração da justiça por parte dos oficiais do Estado, por exemplo, era realizada mediante a incorporação e imitação do que eram consideradas a lei timorense e sua liturgia de administração, conforme suas configurações nos diferentes reinos. $\mathrm{O}$ autor denomina tal fenômeno como racionalidade mimética de governo, expressa numa "pragmática de preservação e repetição [...], um modo de governo da justiça [colonial] moldado à imagem do que se percebia ser a lei timorense", um projeto de governo baseado em "mimetização máxima e modificação mínima das tradições político-jurais locais" (ibidem: 157). Trata-se, assim, de uma tática parasitária, que buscava consolidar a soberania portuguesa na ilha pelo manejo das práticas de governança locais.

Fenômenos relativos à ancoragem de dispositivos de poder modernos em preceitos indígenas de governança também são observados pelo autor em sua análise do modo como as ordens governativas coloniais, denominadas de bandos, eram realizadas na ilha. A execução das ordens coloniais mediante os bandos, para efeitos de guerra ou paz, subordinação cerimonial ou obrigações tributárias, dava-se enquanto performances rituais produzidas pela mobilização de várias mídias, como sons, pessoas e objetos. Tal configuração dos fatos dava-se em razão das condições de eficácia da administração colonial. Nos termos de Roque,

A eficácia e a legitimidade da autoridade colonial encontram-se estritamente ligadas à capacidade de os oficiais governadores portugueses reproduzirem regras de etiqueta e códigos cerimoniais de conduta que os locais entendiam ser obrigatórios, porque

\footnotetext{
${ }^{4}$ A execução do governo por delegação foi uma tática importante da administração colonial do Timor Português, conforme relato de Roque (2012). As práticas de delegação incluíam, muitas vezes, autoridades nativas a quem eram atribuídas pelo Governo português o título de reis ou condecorações militares.
} 
prescritos pela tradição. A gestão correcta deste cerimonialismo era de imensa importância para o governo colonial, inclusive, e em especial, nas relações com as autoridades timorenses. (2012: 570)

Tendo em vista os processos de mútua constituição entre, grosso modo, colonizadores e colonizados, Roque (2012) também coloca em pauta as mimetizações dos bandos portugueses pelas populações leste-timorenses, que teriam criativamente incorporado os mesmos em seus complexos locais de governança. Para o autor, tal incorporação foi facilitada pelo próprio modus operandi da administração portuguesa na ilha, estruturada na dinâmica da delegação e (in)dependência, "que fazia dos liurais/reis a um tempo consumidores, imitadores e corruptores por excelência dos signos, dos objetos e das forças da autoridade emanada de Díli" (Roque, 2012: 580). $\mathrm{Na}$ mimetização indígena dos bandos portugueses, Roque reconhece uma importante mudança litúrgica. Certos signos materiais ganham potência comunicativa e de instauração de ordem, enquanto as palavras perdem poder de comando e comunicação da voz dos liurais. Tal análise demonstra a origem colonial do tara bandu, a despeito da percepção atual de senso comum o tomar como uma prática exclusivamente autóctone de governo.

À luz das evidências sociológicas e históricas acima relatadas, as apropriações contemporâneas de dimensões dos complexos locais de governança por parte do Estado leste-timorense aparecem senão como mais um episódio de um enredo global e de longa duração relacionado à formação e consolidação dos Estados, o qual produz efeitos criativos de difícil predição.

\section{Dinâmicas de estruturação do poder local no Timor-Leste independente}

Minhas abordagens das dinâmicas de estruturação do poder local em Timor-Leste tomam como objetos de reflexão fenômenos relativos às funções de Chefes de Suco e Chefes de Aldeia no país e às dinâmicas eleitorais que os levaram ao poder em 2004/2005 e 2009, bem como à reintrodução do Conselho de Suco, tal como os compreendo a partir da leitura dos trabalhos de Cummins (2010, 2011, 2012), Brown (2012a), Magno e Coa (2012), Gusmão (2012), Tilman (2012), Dos Santos e Da Silva (2012) e Pereira e Koten (2012). Residualmente, discuto também ansiedades administrativas relacionadas à gestão dos mecanismos locais de resolução de conflitos por parte do Estado, dialogando com os trabalhos de Simião (2011, 2012 e 2013), UNDP (2013) e Cummins (2010).

Com sua independência restaurada em maio de 2002, um dos principais desafios do Estado leste-timorense tem sido elaborar uma estrutura administrativa e representativa em todo o território nacional, que funcione também 
como um dispositivo político para incorporação cívica das populações e fortalecimento de sua própria legitimidade. Para tanto, vários estudos têm sido realizados e, aos poucos, planeja-se promover no país a municipalização dos distritos. ${ }^{5}$ Enquanto o Estado realiza os esforços necessários para implantação desse novo sistema administrativo, optou-se pela quase manutenção da divisão territorial e estrutura de poder local legadas pelos Estados coloniais que aí operaram - português e indonésio - com exceção da introdução de eleições livres e democráticas para escolha dos Chefes de Suco e Aldeia e para os membros do Conselho de Suco. Para os níveis administrativos superiores - distritos e subdistritos - o Estado central nomeia os administradores locais que atuarão em seu nome. Para níveis do suco e da aldeia, o Estado institui e reconhece representantes comunitários que, como argumento abaixo, ocupam, de fato, uma posição institucional liminar. Como lembram McWilliam (2008) e Cummins (2010: 199), todas essas figuras institucionais já existiam, de algum modo, no período das colonizações portuguesa ou indonésia, embora os mecanismos oficiais ou oficiosos para escolha das mesmas fossem distintos. ${ }^{6}$ Assim, o território leste-timorense permanece dividido em 13 distritos, 65 subdistritos, 442 sucos e 2225 aldeias (Ministério do Plano e Finanças, 2013).

Pela legislação vigente até o momento em que este artigo é finalizado, as instituições do poder local em operação em Timor-Leste são reguladas pela Lei n. ${ }^{\circ}$ 3/2009. De acordo com tal legislação, as figuras institucionais do poder local - Chefe de Aldeia, Chefe de Suco e Conselho de Suco - são apresentadas como representantes e lideranças comunitárias, sem qualquer vínculo com o Estado. Não obstante, a elas cabem certas funções executivas que normalmente são atribuídas ao Estado. Vejamos alguns exemplos. Atribui-se ao Chefe de Suco a função de:

dirigir as actividades desenvolvidas pela comunidade num determinado suco, em áreas que concorrem para a consolidação da unidade nacional e para a produção de bens e serviços com vista à satisfação das necessidades básicas de vida e desenvolvimento, em estreita articulação com o Conselho de Suco. (Lei n. ${ }^{\circ} 3 / 2009$, Artigo 4)

São apresentadas como áreas de atuação do Chefe de Suco e do Conselho de Suco:

\footnotetext{
${ }^{5}$ A Lei n. ${ }^{\circ}$ 11/2009, aprovada pelo Parlamento Nacional, regula o projeto administrativo a ser implementado em um futuro próximo.

${ }^{6}$ No período da ocupação indonésia os processos eleitorais eram de fachada - não havia espaço para escolher candidatos que não fossem do governo - e tal estrutura administrativa era controlada por uma estrutura militar paralela.
} 
a) Paz e harmonia social; b) Recenseamento e registo da população; c) Educação cívica; d) Promoção das línguas oficiais; e) Desenvolvimento económico; f) Segurança alimentar; g) Protecção do meio ambiente; h) Educação, cultura e desporto; i) Auxílio na manutenção de infraestruturas sociais tais como habitação, escolas, postos de saúde, abertura de poços de água, estradas. (Lei n. ${ }^{\circ}$ 3/2009, Artigo 10, alínea 1)

Parece-me, pois, que a lei trabalha para o cultivo de certa ambiguidade em relação às funções e posições das lideranças locais diante do Estado. Por um lado, ao qualificá-las enquanto representantes comunitárias, o Estado as coloca formalmente fora de sua estrutura administrativa. Por outro lado, ao atribuir às autoridades certas funções executivas permite que as mesmas sejam percebidas como sendo parte ou representantes do Estado, de modo a propiciar que a administração central faça um uso das mesmas de acordo com suas próprias conveniências.

O cultivo de tal ambiguidade não é exclusivo do Estado. Ele pode ser manejado pelas próprias autoridades locais e pelas populações sob sua liderança. Neste contexto, o diagnóstico realizado por Simião (2013), a partir de estudo de caso na aldeia Lisadila, em Maubara/Liquiçá, em 2013, é particularmente expressivo do lugar potencialmente liminar das instituições do poder local nos complexos locais de governança em Timor-Leste. Do ponto de vista da população local, as práticas de resolução de conflitos lideradas por autoridades locais (lia nain, Chefes de Suco ou Aldeia) são consideradas justiça do Estado e assim manejadas por aqueles que protagonizam suas realizações, os quais manipulam ritualmente a Constituição e o Código Penal leste-timorenses em suas performances. Do ponto de vista estatal (polícia e tribunais), contudo, tais práticas são classificadas como mecanismos locais (por oposição aos estatais) de administração da justiça (UNDP, 2013).

De toda a forma, o reconhecimento legal e a incorporação ambígua das lideranças locais nas dinâmicas de governo do país parecem ser mais um capítulo dos processos de integração e incorporação seletiva de autoridades preestabelecidas em redes maiores de interdependência de modo a gerar efeitos de monopolização do poder característicos dos processos de formação do Estado. O fato de o Estado leste-timorense ser, atualmente, o agente promotor das eleições dos representantes comunitários, das legislações que regulam suas funções, assim como a instituição que delega poder a eles - é importante notar que as autoridades locais são empossadas pelo Estado - cria condições para o encapsulamento e controle das autoridades locais pelo poder central, de modo a transformá-las em vias para a sua própria expansão, em um movimento similar ao que Mamdani (1998) sugere ter acontecido em contextos africanos com relação aos chefes tribais. No limite, 
tal fato pode ser a porta de entrada para apropriação de vários elementos dos complexos locais de governança.

A Lei n. ${ }^{\circ} 3 / 2009$ foi promulgada a fim de substituir a Lei n. ${ }^{\circ}$ 2/2004, que até então regulava as instituições do poder local. Comparativamente, a Lei n. ${ }^{\circ}$ 3/2009 introduziu mudanças significativas nos mecanismos eleitorais implicados na escolha das autoridades locais: a apresentação de candidaturas coletivas, no formato de chapas, a partir de 2009, e a despartidarização das candidaturas. A análise das causas que levaram a tais fatos é bastante reveladora de tensões que, possivelmente, atravessam o processo de formação do Estado em Timor-Leste no que diz respeito à sua articulação com níveis secundários de poder.

Do ponto de vista dos jogos políticos das elites de Díli, Cummins (2014, comunicação pessoal) sugere que a despartidarização das eleições foi promovida pelo CNRT (Conselho Nacional de Reconstrução Timorense) de Xanana Gusmão, que previa perdas políticas no ciclo eleitoral de 2009 por não ter uma estrutura de representantes em nível local já consolidada. De outro ponto de vista, a bibliografia sobre o tema indica que questões de ordem distinta podem ter trabalhado para tal configuração dos fatos. De acordo com Cummins (2010: 133-34), Brown (2012b: 161-163), Magno e Coa (2012: 169) e Gusmão (2012: 186) a partidarização das eleições para autoridades locais é vista por parte da população como uma ameaça à manutenção da coesão social, uma vez que desencadearia divisões e conflitos desnecessariamente. A esse respeito, duas hipóteses de pesquisa se colocam no horizonte, uma vez que não foram abordadas em profundidade pela bibliografia: os partidos políticos são tomados como ameaça porque são apropriados como mais uma linguagem para expressão de conflitos sociais preexistentes - e aqui é importante marcar meu distanciamento de perspectivas analíticas que olham para os domínios das aldeias e dos sucos como ambientes coesos e harmoniosos - e/ou a disputa partidária pode criar novas fontes de tensão, desafiando preceitos das (instáveis) ordens locais estabelecidas. Adicionalmente, Cummins (2010: 134) sugere que tal rejeição é alimentada pela memória dos impactos da partidarização da política em 1975 , que gerou a guerra civil, e por certo ressentimento dos habitantes do interior com relação à política de Díli. Conscientes da grande desigualdade que marca o acesso a recursos nos ambientes urbanos e rurais em Timor-Leste, os partidos são vistos muitas vezes como vias de transposição das disputas que têm origem em Díli para as zonas rurais, aumentando mais ainda a sensação de injustiça.

Pode-se ainda dar sentido à rejeição da partidarização da política local por parte da população como uma expressão de resistência às tentativas 
de cooptação das elites baseadas em Díli, quaisquer que sejam as suas filiações partidárias, de modo a manter a autonomia relativa das lideranças locais diante dos jogos de poder na capital. Se for possível sustentar tal hipótese, tal posição talvez seja produto de uma racionalidade política que vê maiores ganhos com a autonomia partidária, dada a própria fragilidade dos serviços localmente oferecidos pelo Estado e do acesso restrito aos seus recursos. Ao discutir as apropriações locais de instituições da democracia representativa em 12 sucos distribuídos entre os distritos de Liquiçá, Ermera, Aileu e Oecussi, Dos Santos e Da Silva (2012: 209-211) destacam a existência de uma demanda compartilhada entre seus interlocutores de que o Estado priorize a disponibilização de bens e serviços que atendam às necessidades básicas das pessoas em vez do estabelecimento de novos mecanismos democráticos. Assim, a rejeição aos partidos pode ser lida como um sinal de agência crítica por parte de setores da população rural em relação aos poucos impactos da administração pública na melhoria das suas condições de vida. No entanto, é preciso registrar que tal crítica convive com múltiplos esforços de consolidação de representações partidárias em nível local. Os eventos chamados de consolidação partidária, nos quais líderes nacionais dos partidos seguem para o interior a fim de empossar representantes locais, realizando ao mesmo tempo comícios que servem para demonstração do poder do partido na região em que a consolidação ocorre, são exemplares da valorização da partidarização da vida política local (Silva, 2009).

O potencial disruptivo da partidarização da política local parece-me ainda poder ser explicado em razão do potencial das palavras e dos discursos entre muitas populações da Indonésia Oriental. Ao contrário da percepção que aborda a fala como representação, como suporte ou expressão de algo que existe fora e antes dela, de modo que ela, a palavra, seria desprovida de agência, em muitos contextos leste-timorenses a palavra tem poder. Assim como as pessoas, o manejo adequado das palavras cria situações, impõe certa ordem das coisas. Nesse contexto, a disputa partidária, muitas vezes elaborada e propalada discursivamente, por meio da mobilização das palavras, pode ser vista, de fato, como criando novos níveis de conflito ou adensando aqueles preexistentes. Em outra oportunidade (Silva, 2010) demonstrei como o discurso anunciado por Xanana Gusmão em maio de 2006 sedimentou e intensificou os termos pelos quais a crise de 2006 foi criada em Díli, gerando efeitos de difusão do conflito em escala nacional de modo a obter a resignação de Mari Alkatiri e a ascensão de Xanana à liderança do poder executivo no país.

Ainda com relação à despartidarização das eleições, parece-me interessante levantar a questão de que o princípio da igualdade formal que 
marca as disputas partidárias possa ser tomado como uma afronta às expectativas de respeito a ordens de precedência, baseadas nas relações entre casas e hierarquias geracionais que informam muitas dinâmicas de reprodução social na Indonésia Oriental (Acciaioli, 2009; Fox, 2009). Em tese, nas disputas políticas estruturadas por filiação partidária os candidatos relacionam-se entre si de forma equânime. Não há hierarquia preestabelecida entre eles e fidelidades primordiais não operam (em tese) na dinâmica da disputa. Ora, tais preceitos podem ser lidos pelas populações locais como desafios à ordem moral da aldeia e do suco, pensada como sagrada e imemorial, que regula, inclusive, aqueles de seus membros que podem exercer funções de autoridade política e ritual. A não observância de tais expectativas pode ser lida como ameaça à reprodução social (Cummins, 2010: 123) em seu sentido mais lato, que envolve a agência de entidades espirituais na vida dos vivos. O desconforto de parte das populações leste-timorenses com o sistema eleitoral multipartidário foi também observado por Hohe (2002a). Para a autora, tal relutância deve-se ao fato de a disputa multipartidária impossibilitar a superação da oposição entre candidaturas por meio de relações de aliança assimétrica. Diante disso, as oposições partidárias são assimiladas em termos dualísticos e acopladas a faccionalizações regionais.

A rejeição à partidarização dos processos de escolha das lideranças comunitárias não significa, contudo, que haja uma visão partilhada de oposição entre instituições de governo tomadas como locais e aquelas pensadas como estatais ou modernas por parte da população. A bibliografia indica a existência de percepções bastante matizadas a esse respeito e um quadro de coexistência e interdependência entre tais instituições. Assim, Magno e Coa (2012: 168, 173), a partir de uma pesquisa realizada em 10 sucos distribuídos entre os distritos de Ainaro, Manufahi, Cova-Lima e Díli, registram a sugestão de seus interlocutores de que não haveria uma oposição entre as instituições de governança locais e a democracia estatal. Segundo os autores, as tecnologias da lisan são pensadas como democráticas (Magno e Coa, 2012 e Tilman, 2012: 195) por alguns; outros interlocutores nativos ainda indicariam que a lisan seja utilizada como instrumento para difusão ou reforço da democracia de Estado. Neste debate, uma questão que se impõe é entender melhor as percepções locais do que seja democracia. Em outro contexto, Cummins (2010: 115) identifica o projeto de que os complexos locais e estatais de governança sejam mantidos como domínios distintos, embora possam e devam colaborar entre si. Justifica-se tal posição em razão de cada um deles estar assente em diferentes fontes de legitimidade e serem mobilizados para resolução de diferentes problemas, em termos ideais. 
A observação das fontes de legitimidade mobilizadas para escolha das lideranças comunitárias sugere também um quadro bastante diverso no país e em processo de transformação. Enquanto em alguns sucos a escolha de determinados candidatos para Chefes de Aldeia e de Suco deriva do fato de o mesmo pertencer à casa à qual é atribuída, por força da lisan, a função administrativa da coletividade (normalmente chamada de casa do liurai, pela bibliografia aqui citada, Cummins, 2010: 116; Magno e Coa, 2012: 167-168; Gusmão, 2012: 182-184; Tilman, 2012: 199, entre outros), em outros lugares evoca-se o critério da capacidade de liderança demonstrada para escolha do líder comunitário. Em alguns casos, observa-se uma sobreposição de fontes de legitimidade, na medida em que historicamente os descendentes das casas de liurais foram também aqueles que tiveram maiores oportunidades de acesso à educação formal, pela qual puderam cultivar ainda mais sua capacidade de liderança (Pereira e Koten, 2012: 228). Em outros casos, adotam-se procedimentos que permitem que o candidato escolhido exerça seu mandato de modo a não contrariar os agentes políticos e espirituais locais, caso ele não tenha vínculo com a casa à qual é atribuído o poder político secular. Magno e Coa (2012: 173) e Dos Santos e Da Silva (2012: 215), por exemplo, relatam o recurso a procedimentos rituais por parte de certas lideranças eleitas junto às casas intituladas do exercício do poder político, pelos quais se autoriza ou delega o direito do exercício do mesmo. Cummins (2010: 127) relata que no Suco de Fatulia, o candidato eleito em 2005 para lia nain no Conselho de Suco teria sido adotado pela casa do liurai a fim de poder exercer suas funções sem afrontar os preceitos da lisan, garantindo assim a segurança da comunidade diante da agência dos ancestrais. ${ }^{7}$ Observa-se, pois que negociações com diferentes princípios de legitimidade se fazem quase sempre necessárias para a constituição do poder das lideranças locais.

Cummins (2012: 118) indica que as apropriações locais de novas instituições de governo desenhadas pelo Estado central estão condicionadas

\footnotetext{
${ }^{7}$ É importante observar que na maior parte da bibliografia consultada para a escrita deste artigo não há referência à problemática da diarquia (princípio de distribuição do poder segundo o qual o poder religioso e o poder secular são exercidos separadamente, por membros de casas intituladas para tal) nas dinâmicas de poder local. Nesse contexto, minha impressão é que o termo liurai é usado como um significante flutuante. Por exemplo, em um caso relatado por Cummins (2010: 127), podemos nos perguntar em que medida o lia nain referido não foi, de fato, adotado pela casa intitulada do exercício do poder religioso. Em Dos Santos e Da Silva (2012: 217) pode-se ver, nas entrelinhas, uma possível acomodação do princípio da diarquia na dinâmica de governança local no Suco de Ponilala, em Ermera. O interlocutor dos mesmos sugere que ali estava em operação uma divisão social do trabalho entre o candidato eleito para Chefe de Suco e o liurai corrente. OChefe de Suco manejaria todas as questões que implicariam relações com o Estado (disputas de terra, por exemplo), enquanto o liurai manejaria questões relacionadas com a lisan.
} 
à forma como estas são lidas como mais ou menos ameaçadoras à lisan ou às relações de poder preexistentes. A recepção das mesmas depende de como os agentes locais percebem o lugar a eles atribuído por tais iniciativas. A autora atribui o relativo sucesso da reintrodução dos Conselhos de Suco no país ao fato de tal instituição se ancorar, ao menos parcialmente, em posições de autoridade preexistentes, as quais, por sua vez, são legitimadas pela força da lisan. Em sua análise a respeito da introdução e efetividade dos Conselhos de Suco nos subdistritos de Ainaro e Venilale, baseada em pesquisa de campo realizada entre agosto de 2008 e janeiro de 2009, Cummins (2010) sugere que tal instituição só funciona minimamente onde sua composição espelha as estruturas de poder preexistentes.

No entanto, na composição dos Conselhos de Suco, tal como regulada por lei, não está em jogo somente a incorporação das lideranças políticas locais, reconhecidas como legítimas porque eleitas pela população. Sua composição visa também empoderar certas posições subalternas de sujeito nos espaços públicos locais, como as mulheres e os jovens. Para tanto têm assentos reservados no Conselho duas mulheres e dois jovens (um de cada sexo). Nesses termos, o Conselho pode ser considerado um suporte para transposição de valores modernos, como a igualdade de gênero e entre gerações, sendo um caso exemplar de como a transposição de projetos de modernidade se dá por meio de negociações com instituições preexistentes. Cummins (2010: 171-178, 2011) se debruça também na análise dos efeitos de tal política de cotas. Do ponto de vista da autora, a política de cotas tem gerado efeitos contrários aos desejados, reforçando, na verdade, discriminações e preconceitos de gênero. Em função do fato de, histórica e simbolicamente, as mulheres não serem reconhecidas como sujeitos políticos nos espaços públicos locais, a participação das mesmas nos Conselhos de Suco tem sido muito pequena e assim o é porque elas não têm liderança fora do Conselho, à diferença dos Chefes de Aldeia e Suco eleitos. Em muitos casos, a participação das mesmas nas reuniões do Conselho se dá mediante a preparação de comida. Porque sentem que não são devidamente consideradas, muitas mulheres eleitas deixam de participar das reuniões. Tais fatos contribuem para a reposição da visão de que as mulheres não têm habilidade para o exercício de liderança local. No caso dos jovens, os mesmos têm sido internalizados como aprendizes ou protegidos dos Chefes de Suco. Também têm pouco poder de argumentação e decisão.

O reconhecimento e a regulamentação dos mecanismos locais de resolução de conflitos constituem também uma dimensão fundamental dos projetos de apropriação e subversão dos complexos locais de governança por parte do Estado leste-timorense. Diferenciando-se de um momento 
anterior do debate em que as práticas locais de administração da justiça eram vistas como concorrentes, opositoras e desafiadoras à justiça moderna (Hohe, 2002b; Simião, 2005, 2011), o debate contemporâneo a respeito da regulamentação das mesmas é caracterizado pelo objetivo de transformá-las em suportes para introdução e respeito a princípios de justiça modernos e de fortalecimento do próprio Estado nacional (Equipe da Divisão Nacional de Assessoria Jurídica e Legislação do Ministério da Justiça, 2013: comunicação pessoal). Para tanto, visa-se, sobretudo, enfraquecer o poder de arbitragem das autoridades locais, de modo a transformá-las em mediadoras, de fato, das partes em conflito, e em vias para promoção da ética dos direitos humanos e dos direitos das mulheres. No entanto, em razão de divergências a respeito do melhor modo de reconhecer ou promover essa incorporação seletiva e transformadora das práticas locais de resolução de conflitos, o Estado até ao momento não aprovou nenhuma política oficial, embora, oficiosamente, muitos operadores das instituições de direito do Estado levem em conta acordos estabelecidos a nível local da administração da justiça (Simião, 2012).

Estudos recentes a esse respeito (Cummins, 2010; UNDP, 2013; Simião, 2013) sugerem que, do ponto de vista local, o recurso a instituições de justiça do Estado (polícia e tribunais) é considerado legítimo somente quando realizado depois da mobilização de mecanismos locais de resolução de conflitos e a partir de certa hierarquia, à exceção de casos criminais (assassinatos ou os que localmente são considerados 'casos grandes'), que normalmente são levados diretamente para a polícia. Assim, o acionamento de mecanismos de resolução de conflitos que extrapolam o domínio da unidade doméstica deve começar pela aldeia, caminhar em direção ao suco e se, ainda assim, os resultados alcançados forem considerados insatisfatórios por uma ou ambas as partes, é considerado socialmente legítimo recorrer-se à polícia e aos tribunais do Estado. Recorrer à polícia e, em decorrência dela, aos tribunais, diretamente, sem antes buscar por negociações a nível local é visto como desrespeitoso, ilegítimo e ameaçador à manutenção das relações que permitem a reprodução da dinâmica social local (UNDP, 2013), podendo acarretar a imposição de multas àqueles que o fazem. ${ }^{8}$ Nesse sentido, o acionamento de certas figurações institucionais do Estado (polícia e tribunais) é vivido como ameaça à reprodução dos laços sociais, podendo gerar efeitos imprevisíveis.

\footnotetext{
${ }^{8}$ Não raramente, inclusive, busca-se validar por mecanismos locais de resolução de conflitos decisões tomadas pelos tribunais a fim de que estas não impliquem rupturas no tecido social.
} 


\section{Usos contemporâneos do tara bandu}

De um modo sintético, o tara bandu ('dependurar proibição') pode ser descrito como um dispositivo local de governança que opera pela imposição ritual de regras e proibições. Nos rituais que o instituem tomam parte autoridades locais e nacionais, bem como entidades espirituais às quais se credita, em seu conjunto, agência nos processos de reprodução social. Em tais ocasiões, são realizados sacrifícios e falas rituais. Tais procedimentos têm como objetivo instaurar canais de comunicação entre as autoridades (vivas e mortas) presentes e validar publicamente as proibições prescritas, as quais são lidas em alta voz para a comunidade (Yoder, 2007: 47) e inscritas em símbolos, que são a seguir fixados nas áreas de cobertura do tara bandu. Além de instaurar proibições relativas a relações entre seres humanos e meio ambiente, seres humanos e instituições públicas e entre seres humanos e seres humanos, o tara bandu também institui punições àqueles que desobedecerem às ordens prescritas. A despeito de sua origem colonial, como bem demonstra Roque (2012), o tara bandu tem sido considerado como eminentemente local pelos vários atores envolvidos em sua configuração e manejo contemporâneo.

O reconhecimento e estímulo às práticas de tara bandu no Timor-Leste pós-ocupação indonésia derivavam, em um primeiro momento, de preocupações relacionadas à preservação e manejo do meio ambiente (Yoder, 2007; De Carvalho e Correia, 2011). Entretanto, o incentivo à retomada de tal dispositivo ganhou novo fôlego a partir de 2006. Considerada, desde o ponto de vista do Estado, uma tecnologia local de governança eficaz para recomposição da ordem para além da relação com o meio ambiente, o Estado leste-timorense e algumas agências de cooperação internacional passaram, a partir dos últimos meses de 2006, a disponibilizar recursos para realização de tara bandu em Díli e em outros distritos do país, criando para tanto um novo órgão de governo no Ministério da Solidariedade Social, a Secretaria de Coesão Social (UNDP, 2013: 34-35, 62). ${ }^{9}$ O tara bandu passou então a ser considerado um instrumento de pacificação entre grupos em conflito (jovens envolvidos com gangues e outras associações políticas) e, posteriormente, uma tecnologia de construção e manutenção da ordem, em um contexto de crise institucional das forças de segurança do Estado. Assim, a fim de superar a crise de governança produzida em 2006, o Estado passou a estimular a elaboração de "leis" de alcance local (com jurisdição no domínio

\footnotetext{
${ }_{9}$ Como Yoder (2007) demonstra, no período que antecede 2006 era o Ministério da Agricultura, Florestas e Pescas o órgão de governo que disponibilizava recursos para tara bandu, uma vez que tal dispositivo era tomado como voltado eminentemente à gestão das florestas e outros elementos do meio ambiente.
} 
dos sucos ou de um conjunto de sucos), construídas e consensuadas pelos representantes comunitários e outras autoridades locais, a partir de alguma consulta popular e junto aos órgãos do Estado. No espaço desta seção proponho a análise do conteúdo de três tara bandu, dois deles operantes em Díli e outro em Ermera.

Apresentando como justificativas a necessidade de promover o desenvolvimento, conforme prevê a Constituição e as leis dela derivadas, bem como a obrigação de todos participarem na formação da nação, a administração do subdistrito do Cristo Rei, em Díli, instaurou um tara bandu em 18 de junho de 2009. Constituído por 23 artigos, o tara bandu institui proibições e sanções a todos os habitantes deste subdistrito. Destacam-se, entre as proibições:

1. Não se podem violar os direitos humanos das crianças, dos adultos e dos anciãos; 2. Não se pode fazer violência doméstica física e psíquica, bem como violência sexual contra as mulheres; violência física dentro de casa; gozar das raparigas no espaço público, fazer uso de palavras ofensivas que diminuam a dignidade das pessoas [...] 3. Não se deve beber bebidas alcoólicas de modo a ficar bêbado e provocar problemas [...] 10. Não se deve vender sua terra/propriedade de forma arbitrária porque nossa terra/propriedade é nossa herança para o futuro [...] 13. Não se pode jogar lixo nos rios; [...] 17. Não se pode viver como pessoas que não sabem ler nem escrever; [...] 23. Aqueles que violarem a cultura tara bandu receberão sanções conforme definidas pela cultura e tradição legadas pelos ancestrais do suco ou da aldeia em que o infrator habita. (M.A.E.O.T. et al., 2009) ${ }^{10}$

Já o tara bandu consensuado entre aldeias pertencentes aos sucos do Bairro Pité e Comoro, composto por oito artigos, impõe não somente proibições, mas também obrigações para a população e para as autoridades comunitárias. Além de replicar parte das proibições previstas no subdistrito do Cristo Rei, este tara bandu ainda sugere:

Artigo $1^{\circ}$. Dos deveres do cidadão na aldeia ou suco. 1. Não se pode receber convidados ou alugar a casa para família de estrangeiros por tempo superior a seis meses, sem antes comunicar às autoridades comunitárias. Se assim o fizer será aplicada multa de 25 dólares por pessoa recebida e o caso será levado à polícia se tal evento desencadear algum problema comunitário [...] 3. Os membros da comunidade acima de 17 anos devem ter cartão eleitoral ou bilhete de identidade de Timor-Leste. Aqueles que não tiverem tais documentos não serão atendidos pelo Chefe de Suco e Chefe de

$\overline{10}$ Tradução livre do original em tétum. 
Aldeia para fins de resolução de seus interesses privados; [...] 4. Não se pode incriminar as pessoas como bruxas. Quem o fizer pagará multa na forma de bebidas, tais, ou animais pequenos ou grandes, a depender do tamanho do seu erro. [...] Artigo 7. Amar o meio ambiente. [...] Não se pode queimar a terra, caçar animais selvagens, cortar e trazer lenha das montanhas, de árvores localizadas em propriedades privadas [...] estragar canos e torneiras de água [...]. (Regulamento, 2011) $)^{11}$

Esta pequena amostra de artigos revela ao menos três dos usos contemporâneos do tara bandu que trabalham para fins de pacificação e de fortalecimento da estrutura administrativa do Estado, bem como da moralidade que o sustenta. O tara bandu é mobilizado para evitar ou controlar a emergência de novos conflitos comunitários, para fortalecer a autoridade das lideranças comunitárias e para indicar a necessidade de respeito à propriedade privada e observância de valores modernos relacionados à igualdade de gênero (punem-se aqueles que pratiquem violência doméstica e desrespeitem os direitos humanos) e à preservação do meio ambiente. Estamos, pois, diante de usos de um elemento dos complexos locais de governança, financiados pelo Estado, pelos quais o Estado introduz novas moralidades, realiza sua ação de governo e, assim, potencialmente aumenta seu grau de legitimidade e capilaridade no tecido social.

Com o objetivo de promover o desenvolvimento econômico, a segurança alimentar e a proteção ao meio ambiente (Akta, 2012), autoridades locais ligadas a diferentes instituições no distrito de Ermera - Igreja católica, organizações não governamentais, Estado - trabalharam juntas a fim de elaborar princípios gerais para um tara bandu de alcance distrital, o qual, esperava-se, seria regulamentado de forma mais detalhada em cada um dos subdistritos ou sucos que o compõem. Segundo Pascoela Aida da Costa Exposto, diretora da organização Feto Kiik Servisu Hamutuk (FKSH, Mulheres Jovens Trabalhando Juntas), tal iniciativa se consolidou em razão da constatação dos altos índices de pobreza entre a população de Ermera, a despeito do grande potencial de produção de riqueza da região em razão das plantações de café. De acordo com ela, tal configuração dos fatos seria decorrência dos grandes investimentos realizados pela população em práticas rituais, os quais necessitavam de algum controle externo a fim de propiciar um tipo de acumulação material que permitisse às pessoas melhorar suas condições de vida, de modo a ter segurança alimentar, prover educação escolar aos seus filhos, cuidar de sua saúde, etc. Nesse sentido, além de temas recorrentes nas experiências de tara bandu analisadas acima, uma das dimensões mais

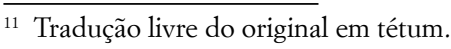


importantes do tara bandu de Ermera, para os fins de governo explicitados há pouco, reside na tentativa de controle de investimentos rituais.

O tara bandu em Ermera regula, de forma mais abrangente, três tipos de relações diferentes: relações das pessoas com a natureza; relações das pessoas com os animais e relações entre as próprias pessoas. Assim, proíbe-se, por exemplo, a colheita de frutas não maduras (Akta, 2012: Parte $1 \mathrm{Ab}$ ), a destruição de bens públicos (Akta, 2012: Parte I Ae), caça de animais selvagens em terras secas ou alagadas protegidas pela comunidade (Akta, 2012: Parte II Ac), relações sexuais com crianças entre os 5 e os 15 anos (Akta, 2012: Parte III Aa) e tráfico humano (Akta, 2012: Parte III Ae). Chama a atenção, contudo, uma dimensão das proibições voltadas à relação entre pessoas. A proibição de realização de rituais de desluto (kore metan) e outras modalidades de istilo (rituais), durante os oito anos que seguem à instauração do tara bandu (Akta, 2012: Parte III Bd), ou seja, até 2020. O tara bandu proíbe também a imposição de quantidades específicas de animais para sacrifício em rituais fúnebres, quando as partes envolvidas (em geral doadores e tomadores de mulheres de diferentes gerações) negociam as dádivas a serem ofertadas para tal fim. Sugere-se explicitamente que a quantidade de animais a serem sacrificados deve depender sempre das capacidades dos descendentes diretos da família do defunto/ da defunta (Akta, 2012: Parte III Be).

A instauração do tara bandu de Ermera foi realizada por meio de uma grande cerimônia, na qual se fizeram presentes o bispo de Díli, Dom Alberto Ricardo, bem como o então Presidente da República, José Ramos Horta. Desde então, tal evento parece ser olhado com atenção por autoridades de Díli e da região de Ermera, sendo objeto de avaliações e comentários em diferentes partes do país. Por ocasião do aniversário de seis meses do tara bandu, foi realizada em Ermera uma reunião de avaliação a respeito de seus impactos. A minuta da reunião expressa bem os objetivos buscados pelas diferentes agências (Estado, Igreja, organizações não governamentais) envolvidas em sua concepção, indicando os modos pelos quais ele serve de suporte para transposição de projetos modernos de organização social e subjetivação. Grosso modo, um tom celebratório faz-se presente em todas as avaliações relatadas neste documento, o qual serve de base para legitimar o desenvolvimento de outras táticas regulatórias sobre outras dimensões dos complexos locais de governança, como as trocas matrimoniais e as fases dos rituais fúnebres que antecedem o desluto (Kore metan).

Do ponto de vista das autoridades eclesiais, os indicadores destacados como efeitos positivos do tara bandu em Ermera são: 1. aumento do tempo de trabalho aplicado à secagem de café pela população; 2 . redução dos 
maus gastos das pessoas com os rituais no período da colheita do café, que levariam à chamada corrupção cultural; 3 . aumento da disciplina de e para o trabalho por parte da população. Os chamados maus gastos referem-se, neste contexto, a investimentos rituais considerados excessivos, manifestos no sacrifício de um grande número de animais ou na doação de muito dinheiro (via o regime da dádiva) para efeitos de construção ou reposição de alianças entre doadores e tomadores de mulheres, para além de outros fins. O aumento do número de animais sacrificados ou aumento da circulação de dinheiro para dinâmicas de reprodução social locais qualifica o que se denomina como corrupção cultural (Revisaum, 2012:1-2).

Além de citar, mais uma vez, os impactos do tara bandu para o aumento da produção de café na região, o administrador do distrito de Ermera sugeriu que o ritual estaria contribuindo para consolidar as fronteiras distritais. Como indicado anteriormente, a execução do tara bandu implica a exibição pública (o dependurar) de símbolos que evocam as proibições por ele impostas nos limites territoriais em que elas operam. Assim, a distribuição dos símbolos do tara bandu de Ermera nos limites territoriais do distrito estaria contribuindo para o aumento da consciência dos limites territoriais do próprio distrito. Não obstante, o administrador também destacou o fato de algumas pessoas avaliarem tal tara bandu como um dispositivo ditatorial, ilegítimo em tempos de democracia (ibidem: 2). Tal avaliação foi também relatada pelo representante da organização não governamental Hametim democracia no igualdade (Consolidar a democracia e a igualdade), presente na reunião. Na percepção do administrador do subdistrito de Hatualia, a dimensão mais desafiadora na implementação do tara bandu seria aquela que diz respeito às relações entre as pessoas (ibidem: 3). Nesse sentido, ele demandou às autoridades e aos representantes comunitários ali presentes novas regulamentações, voltadas explicitamente às prestações matrimoniais e às primeiras fases dos rituais fúnebres. Por fim, outro representante de organizações não governamentais destacou os efeitos de pacificação do tara bandu. Segundo ele, teria havido uma diminuição do número de casos de conflito encaminhados ao Chefe de Suco para resolução. Sugeriu, ainda, que a diminuição do número de conflitos estaria contribuindo indiretamente para melhoria das condições econômicas da população, pois se fazendo desnecessárias cerimônias para resolução de conflitos não era preciso dispor de animais nem de outras modalidades de recursos para fins de pagamento de multas ou reconciliação (ibidem: 3-4).

Com base em tais avaliações, pode-se concluir que o tara bandu em Ermera visa, e em alguma medida implica, a domesticação e o controle das condutas individuais e coletivas de modo a produzir corpos e outras modalidades 
de recursos voltados à produção para e pelo trabalho. Tal fato parece ser cultivado e estimulado pelo controle das práticas rituais, sobretudo pelo controle dos recursos nelas investidos. Paralelamente, celebram-se os efeitos de pacificação produzidos pelo tara bandu, que facilitariam a governança local. Tais efeitos de pacificação trabalham também a favor da acumulação de outros recursos que permitiriam às pessoas a saída de sua condição de vulnerabilidade e participação em outras instituições civilizatórias, como a escola, por exemplo.

Dadas as avaliações e demandas apresentadas na reunião de avaliação de seis meses do tara bandu de Ermera, o coletivo de governo ali presente decidiu pela inserção de duas novas proibições em seu interior: proibiu-se a realização de prestações matrimoniais que, em sua totalidade, fossem superiores a 2500 dólares. Prevê-se que o desrespeito desse limite implica pagamento de multa no dobro do valor dispendido e proibição de realização de desluto e outras modalidades rituais por 16 anos. Impôs-se também o limite de sacrifícios de animais para cerimônias fúnebres que vão do velório até o que, em tétum, é chamado de ai-funan midar. ${ }^{12}$ Para tanto, pode-se sacrificar, no máximo, dois búfalos, dois porcos e dois cabritos. O desrespeito de tais limites implica pagamento de multas, de modo que se forem sacrificados três búfalos a multa consistirá em dois búfalos, acrescidos de 1000 dólares. Se forem sacrificados quatro búfalos, quatro búfalos também devem ser pagos como multa, acrescidos de mais 2000 dólares e outros animais. Em ambos os casos, os infratores ficam proibidos de praticar rituais por 16 anos (Revisaum, 2012: 4-5).

Por ocasião do aniversário de um ano deste tara bandu, foi publicada uma matéria especial no sítio eletrônico semioficial da Presidência da República em Timor-Leste, no qual se registraram as avaliações de autoridades envolvidas em sua execução. Entre outras coisas, o administrador de Ermera destacou os grandes efeitos positivos do ritual para diminuição da violência e de conflitos entre a população bem como do percentual de pessoal em situação de grande vulnerabilidade (com fome ou sem casa). Isso porque o tara bandu teria como consequência aumento do tempo investido pelas pessoas na produção de alimentos e de café. Ele ressaltou também

\footnotetext{
${ }_{12}$ Em diferentes contextos leste-timorenses os rituais fúnebres vão muito além do velório e do enterro. São realizados mediante rituais que marcam diferentes momentos da passagem do defunto/ defunta para outros domínios de existência, pelos quais os mesmos vão adquirindo diferentes status diante dos vivos. Há grande variação nas intensidades, configurações e temporalidades relacionadas à execução de tais rituais entre as populações leste-timorenses. Entre algumas delas, denomina-se aifunan moruk (flor amarga) o primeiro ritual realizado depois do enterro do corpo e de aifunan midar (flor doce) o ritual seguinte. Ambos antecedem o desluto (kore metan).
} 
o aumento do número de crianças nas escolas e melhorias nas condições de saúde da população, de modo geral..$^{13}$

\section{Considerações finais}

Ao longo deste artigo procurei apontar algumas tendências que marcam tentativas de apropriação por parte do Estado leste-timorense de elementos dos complexos locais de governança, nomeadamente as instituições do poder local e a prática do tara bandu. Tal exercício foi realizado por meio de revisão bibliográfica e análise documental.

No que diz respeito às instituições do poder local, destaquei em minha argumentação a posição ambígua em que o Estado coloca as autoridades locais e as práticas de resolução de conflitos por elas gerenciadas. Por um lado, as autoridades locais estão fora do Estado. Em termos legais, elas não são mais do que representantes comunitárias. Ao mesmo tempo, a elas são delegadas funções executivas relacionadas à gestão do Estado, como recenseamento e registro da população ou proteção do meio ambiente, bem como ações ligadas à formação da nação - entre suas funções consta a promoção das línguas oficiais. Tal ambiguidade faz-se também presente no silêncio do Estado com relação ao modo como suas instituições de justiça reconhecem ou não as práticas locais de resolução de conflitos.

O silêncio e a ambiguidade identificados criam condições para múltiplos discursos, leituras e combinações entre os elementos estatais e os complexos locais de governança que deixam espaços abertos para negociações contextuais que por sua vez permitem responder a vários interesses políticos em jogo. Provavelmente, esses espaços vazios ou ambíguos são fundamentais para a sedimentação da estabilidade política no país. Além disso, o fato de ser o Estado aquele que empossa as autoridades locais e regulamenta as funções das mesmas indica uma tendência de monopolização do poder sobre elas e, por consequência, das fontes locais de autoridade e governança de modo a reconfigurá-las, uma vez que elas são encapsuladas em novas redes de interdependência. Nesse sentido, impõe-se a necessidade de pensar, no futuro, as implicações do processo de transformação nas dinâmicas híbridas de governança advindas da municipalização dos distritos. Estará implicada no processo de municipalização uma maior monopolização dos instrumentos de governo por parte do Estado?

Procurei também sistematizar a resistência de setores das populações rurais à partidarização das disputas políticas a nível local, procurando

${ }_{13}$ Matéria consultada a 20.03.2013, em http://aitaraklaranlive.wordpress.com//?s=tara+ bandu\&search $=$ Go. 
conectar análises realizadas por meus interlocutores com questões derivadas de pesquisas antropológicas na região. A esse respeito, ressalto os modos pelos quais a competição partidária e suas manifestações discursivas podem ser experimentadas como um risco para a reprodução de preceitos de distribuição e exercício do poder locais, pensados como imemoriais e sagrados, muitas vezes assentes em preceitos de hierarquia e diarquia entre casas. Por outro lado, destaquei também as inúmeras acomodações que estão acontecendo, de modo a permitir a coexistência, coabitação entre diferentes fontes de poder e autoridade política a nível local.

Como vimos acima, alguns dos usos contemporâneos do tara bandu servem claramente a fins de pacificação e fortalecimento da legitimidade e da estrutura administrativa do Estado, tendo sido mobilizados a fim de recompor a ordem social após a crise de 2006. O caso de Ermera é ainda mais potente, do ponto de vista hermenêutico, por revelar o modo como o tara bandu tem sido mobilizado para provocar alterações em uma dimensão fulcral dos padrões locais de reprodução social, quais sejam, as práticas rituais relacionadas à construção de alianças e manejo das relações com entidades espirituais.

A mobilização da Kultura para efeitos de governo e empoderamento não é, contudo, prerrogativa do Estado. Tal dimensão de análise foi privilegiada neste artigo porque antes constatei alguns dos modos como atores políticos locais fazem uso dos recursos disponibilizados pelo Estado para reconstrução das casas sagradas e realização de rituais com fins de gerar efeitos de poder (Silva e Simião, 2012). De fato, é esta a outra perspectiva que tem ocupado lugar de destaque na produção contemporânea a respeito das práticas de governança no Timor-Leste contemporâneo, tal como presentes nas abordagens de McWilliam (2008, 2011), Yoder (2007), Palmer e de Carvalho (2008), Cummins (2010, 2011, 2012), entre outros. A esse respeito, Yoder (2007) demonstra como os processos envolvidos na elaboração e execução do tara bandu em Oecussi, entre 2001 e 2004, serviram também à restituição do poder e do reconhecimento a certas autoridades locais, processo este por meio do qual o Estado também aumentava seu espectro de governança e legitimidade. Assim, as práticas híbridas de governança serviam, naquele contexto, para o mútuo fortalecimento e reconhecimento (Cummins, 2011) das partes que as constituíam, efeito este alcançado por meio de mútua parasitação (Roque, 2010a). Palmer e de Carvalho (2008: 1322), por sua vez, destacam que os efeitos de fortalecimento do poder das autoridades locais por meio da realização de rituais não se restringe aos domínios locais. Potencialmente, podem servir como alavanca para geração de reconhecimento e poder em espaços nacionais.

Os efeitos de poder advindos da mobilização de dimensões dos complexos locais de governança, enquanto kultura, por parte dos atores locais, só é 
possível porque seus interlocutores reconhecem naquilo que entendem como cultura uma fonte de poder, identidade e governo. Em outros termos, porque a diferença cultural tem sido, desde o período colonial e em diferentes contextos, tomada como justificativa para legitimar práticas de governo e poder. Para tanto, múltiplos atores, locais, nacionais e transnacionais, empenham-se em projetos e processos de objetivação e objetificação da cultura de modo a torná-la tangível e daí extrair efeitos políticos. Esses são ao menos parte dos fatos presentes no que genericamente tem sido denominado como reavivamento da cultura, ou das tradições em dimensão global. ${ }^{14}$ Os efeitos individuais e coletivos advindos de tais esforços são imprevisíveis e estão na pauta do dia na agenda de pesquisa em antropologia.

Neste contexto, o caso leste-timorense é particularmente interessante na medida em que é produto de ações coloniais de diferentes origens e das reações a elas, uma vez que a própria restauração da independência é por muitos interpretada como efeito da força da lisan, dos usos e costumes, da kultura (Hicks, 2007: Barnes, 2010; Silva e Simião, 2012). E há nisso verdade, inclusive desde o ponto de vista de um discurso político moderno desencantado. As demandas de independência política ao Timor-Leste ocupado pela Indonésia eram difundidas internacionalmente pelos movimentos de resistência na diáspora através do cultivo de imagens de unidade ou particularidade cultural apresentadas como violadas, imagens que articulavam características das formas de reprodução social indígenas com legados da colonização portuguesa. Como o próprio desfecho de tais iniciativas revela - criou-se em torno da questão leste-timorense uma forte rede de solidariedade internacional e a independência do país foi de fato restaurada - pode-se dizer que, em alguma medida, a kultura teve sua agência. Entender os efeitos da cultura, em que pese toda a sua polissemia, como categoria de governo no mundo contemporâneo é um desafio epistemológico que pede o engajamento de muitos de nós.

Artigo recebido a 31.03.2014

Aprovado para publicação a 09.07.2014

\footnotetext{
${ }^{14}$ Segundo Davidson e Henley (2007), o revivalismo da categoria adat na Indonésia contemporânea deve-se a quatro fenômenos: 1 . o apoio financeiro e moral das redes e organizações internacionais comprometidas com o direito das populações indígenas; 2 . os processos de democratização e descentralização do Estado na Indonésia pós-Suharto; 3. o papel positivo que a ideia de adat tem tido no processo de imaginação nacional indonésio; 4. o histórico de opressão das populações marginalizadas sob o regime da Nova Ordem. Para o caso leste-timorense, o reavivamento e fortalecimento de práticas tidas como tradicionais ou costumeiras de reprodução social são também explicados como decorrência da restauração da independência, fato histórico atribuído por muitos ao poder da lisan e de seus agentes, aos quais se faz necessário pagar os devidos tributos (Hicks, 2007; Barnes, 2010; Silva e Simião, 2012).
} 


\section{Referências bibliográficas}

Acciaioli, Greg (2009), "Distinguishing Hierarchy and Precedence. Comparing Status Distinctions in South Asia and Austronesian World, with Special Reference to South Sulawesi", in Michael Vischer (org.), Precedence: Social Differentiation in the Austronesian World. Canberra: ANU E Press, 52-90.

Barnes, Susana (2010), "Nation-building and the 'Resurgence of Custom'”, in Damian Grenfell et al. (org.), Nation-building across the Urban and Rural in Timor-Leste. Conference Report. Melbourne. RMIT University and Australian Volunteers International. Consultado a 10.06.2012, em http://cultura.gov.tl/sites/default/files/ Conference_report_English_web_combined.pdf\#page=14.

Boege, Volker; Brown, M. Anne; Clements, Kevin P. (2009), "Hybrid Political Orders, Not Fragile States", Peace Review: A Journal of Social Justice, 21(1), 13-21.

Brown, M. Anne (2012a), "Entangled Worlds: Village and Political Community in Timor-Leste”, Local Global. Identity, Security, Community, 11, 54-71.

Brown, M. Anne (2012b), "Hybrid Governance and Democratization - Village Governance in Timor-Leste”, Local Global. Identity, Security, Community, 11, 156-164.

Cummins, Deborah (2010), "Local Governance in Timor-Leste: The Politics of Mutual Recognition”. Tese de doutoramento apresentada à School of Social Sciences and International Studies, University of New South Wales, Austrália.

Cummins, Deborah (2011), "The Problem of Gender Quotas: Women's Representatives on Timor-Leste suku Councils", Development in Practice, 21(1), 85-95.

Cummins, Deborah (2012), "Multiple Realities: The Need to Re-think Institutional Theory”, Local Global. Identity, Security, Community, 11, 110-122.

Davidson, J.; Henley, D. (2007), The Revival of Tradition in Indonesian Politics: The Development of Adat from Colonialism to Indigenism. London: Routledge.

De Carvalho, Demetrio Amaral; Correia, Jose (2011), "Tara Bandu as Traditional Ecological Knowledge", in Demetrio do Amaral de Carvalho (org.), Local Knowledge of Timor. Jakarta: Unesco Jakarta, 57-67.

Dos Santos, Abel Boavida; Da Silva, Elda (2012), "Introduction of a Modern Democratic System and its Impact on Societies in East Timorese Traditional Culture”, Local Global. Identity, Security, Community, 11, 206-220.

Dumont, Louis (1977), From Mandeville to Marx (Homo Aequalis I). Chicago: University of Chicago Press.

Dumont, Louis (1983), Essais sur l'individualisme. Une perspective anthropologique sur l'idéologie moderne. Paris: Seuil.

Durkheim, Émile (1993), Lições de sociologia: a moral, o direito e o Estado. São Paulo: EDUSP.

Elias, Norbert (1993), O processo civilizador. Rio de Janeiro: Jorge Zahar Ed.

Fox, James (2009), "Precedence in Perspective", in Michael Vischer (org.), Precedence: Social Differentiation in the Austronesian World. Canberra: ANU E Press, 1-11. 
Gusmão, Alex (2012), “Electing Community Leaders: Diversity in Uniformity”, Local Global. Identity, Security, Community, 11, 180-191.

Hicks, David (2007), "Community and Nation-state in East Timor", Antbropology Today, 23, 13-16.

Hohe, Tanja (2002a), “'Totem Polls': Indigenous Concepts and 'Free and Fair' Elections in East Timor”, International Peacekeeping, 9(4), 69-88.

Hohe, Tanja (2002b), "The Clash of Paradigms: International Administration and Local Political Legitimacy in East Timor", Contemporary Southeast Asia, 24(3), 569-589.

Latour, Bruno (1994), Jamais fomos modernos. Rio de Janeiro: Ed. 34.

Magno, José da Costa; Coa, Antonio (2012), "Finding a New Path between lisan and Democracy at the suku Level”, Local Global. Identity, Security, Community, 11, 166-178. Mamdani, Mahmood (1998), Ciudadano y súbdito. África contemporánea y el legado del colonialismo tardío. Madri: Siglo XXI Editores.

Mauss, Marcel (1974), "Ensaio sobre a dádiva", in Sociologia e antropologia, vol. II. São Paulo: Editora Pedagógica e Universitária Ltda, 37-184.

McWilliam, Andrew (2008), "Customary Governance in Timor-Leste”, in David Mearns (org.) Democratic Governance in Timor-Leste. Reconciling the Local and the National. Darwin: Charles Darwin University Press, 129-142.

McWilliam, Andrew (2011), "Exchange and Resilience in Timor-Leste", Journal of the Royal Antbropological Institute, 17(4), 745-763.

Ministério do Plano e Finanças/RDTL (2013), Timor-Leste em números 2012. Consultado a 25.03.2014, em http://www.laohamutuk.org/DVD/DGS/TLFigures2012.pdf.

Palmer, Lisa; de Carvalho, Demetrio do Amaral (2008), "Nation Building and Resource Management: The Politics of 'Nature' in Timor-Leste”, Geoforum, 39, 1321-1332.

Pereira, Martinho; Koten, Maria Madalena (2012), "Dynamics of Democracy at the suku Level”, Local Global. Identity, Security, Community, 11, 222-232.

Poggi, Giofrancesco (1978), The Development of Modern State. A Sociological Introduction. Stanford: Stanford University Press.

Roque, Ricardo (2010a), Headbunting and Colonialism. Anthropology and the Circulation of Human Skulls in the Portuguese Empire, 1870-1930. Basingstoke: Palgrave Macmillan.

Roque, Ricardo (2010b) “The Unruly Island: Colonialism's Predicament in Late Nineteenth-century East Timor”, Portuguese Literary and Cultural Studies, 17/18, 303-330.

Roque, Ricardo (2011), "Etnografias coloniais, tecnologias miméticas: a administração colonial e os usos e costumes em Timor-Leste no final do século XIX”, in Kelly Silva; Lúcio Sousa (orgs.), Ita maun alin ... O livro do irmão mais novo. Afinidades antropológicas em torno de Timor-Leste. Lisboa: Edições Colibri, 155-168.

Roque, Ricardo (2012), “A voz dos bandos: colectivos de justiça e ritos da palavra portuguesa em Timor-Leste colonial”, Mana, 18(3), 563-594. 
Silva, Kelly (2009), "Reciprocity, Recognition and Suffering: Political Mobilizers in Independent East Timor”, Vibrant - Virtual Brazilian Antbropology, 5(2), 156-178. Silva, Kelly (2010), "Processes of Regionalisation in East Timor Social Conflicts", Anthropological Forum, 20, 105-123.

Silva, Kelly; Simião, Daniel (2012), “Coping with 'Traditions': The Analysis of East-Timorese Nation Building from the Perspective of Certain Anthropology made in Brazil", Vibrant, 9(1), 360-381. Consultado a 14.07.2014, em http://www. scielo.br/scielo.php?script=sci_arttext \&pid=S1809-43412012000100013\&lng=pt $\& n r m=$ iso.

Simião, Daniel S. (2005), As donas da palavra: gênero, justiça e a invenção da violência doméstica em Timor-Leste. Tese de doutoramento apresentada à Universidade de Brasília - UnB, Brasília, Brasil.

Simião, Daniel S. (2011), "Sensibilidade jurídica e diversidade cultural: dilemas timorenses em perspectiva comparada", in Kelly Silva; Lucio Sousa (orgs.), Ita Maun Alin: o livro do irmão mais novo. Lisboa: Colibri, 113-129.

Simião, Daniel S. (2012), Sé Mak Sala Tenkeser Selu Sala: desafios de justiça, direitos e diferenças em Timor-Leste. Documetário. NTSC, cor. 36 min. Brasil, Timor-Leste. Consultado a 25.03.2014, em http://youtu.be/CyKnw2Vgz6M.

Simião, Daniel S. (2013), "Agency, Gender and Individuation: Tensions between Law and Legal Sensibilities in Timor-Leste”, apresentado no simpósio internacional "Dynamics of Power in Timor-Leste”, organizado pelo CES, Lisboa, junho 28-29.

Tilman, Mateus (2012), "Customary Social Order and Authority in the Contemporary East Timorese Village: Persistence and Transformation”, Local Global. Identity, Security, Community, 11, 192-205.

Yoder, Laura S. Meitzner (2007), "Hybridising Justice: State-Customary Interactions over Forest Crime and Punishment in Oecusse, East Timor", The Asia Pacific Journal of Anthropology, 8(2), 43-57.

UNDP (2013), Breaking the Cycle of Domestic Violence in Timor-Leste. Access to Justice Options, Barriers and Decision Making Processes in the Context of Legal Pluralism. Consultado a 25.03.2014, em http://www.tl.undp.org/content/timor_leste/en/home/ ourwork/democraticgovernance/TL_DG_AboutJSP/TL_DG_Justice_reports_ papers/_jcr_content/contentPar/download_0/file.res/Domestic\%20Violence $\% 20$ Report \%20\%255bwith\%20cover\%20FINAL\%255d.pdf.

\section{Documentos primários}

Akta no regulamentu Tara Bandu Distrito Ermera (2012), mimeo.

Cummins, Deborah (2014), Research doc., mensagem recebida pela autora a 14.02.2014. Equipe da Divisão Nacional de Assessoria Jurídica e Legislação do Ministério da Justiça (2013), Entrevista qualitativa semiestruturada realizada em fevereiro de 2013 por Kelly Cristiane da Silva. 
150 | Kelly Silva

Lei n. ${ }^{\circ}$ 3/2009 Lideranças Comunitárias e a sua eleição. Promulgada pelo Parlamento Nacional em 8 de julho de 2009.

Lei n. ${ }^{\circ}$ 2/2004 sobre Eleição dos Chefes de Suco e dos Conselhos de Suco. Promulgada pelo Parlamento Nacional a 10 de fevereiro de 2004.

Revisaum Regulamentu Tara-Bandu (Rezultado Evaluasaum Fulan ne'en) (2012), mimeo.

Regulamento/Norma Kultura Tara Bandu ba 11 (sanulu resin ida) aldeia nebe pertencia ba iha Manleuana Suco Bairro-Pite no Comoro (2011).

M.A.E.O.T. et al. (2009), Regulamentu/Norma Kultura Tara Bandu Cristo Rei. Mimeo. 